\title{
A Structural Functional Model for Managing the Digital Potential of a Strategic Innovatively Active Industrial Cluster
}

\author{
Aleksander Babkin ${ }^{1}$, Larissa Tashenova ${ }^{2 *}$, Dinara Mamrayeva ${ }^{2}$, Tamara Andreeva ${ }^{3}$ \\ ${ }^{1}$ Institute of Industrial Management, Economics and Trade, Graduate School of Industrial Economics, Peter the \\ Great St. Petersburg Polytechnic University, Polytechnicheskaya Str., 29, St. Petersburg 195251, Russia \\ ${ }^{2}$ Faculty of Economics, Marketing Department, Y.A. Buketov Karaganda University, Universitetskaya Str., 28, \\ Karaganda 100028, Kazakhstan \\ ${ }^{3}$ Institute of Economics and Organization of Industrial Production of the Siberian Branch of the Russian Academy \\ of Sciences, pr. Ak. Lavrentieva, 17, Novosibirsk 630000, Russia
}

\begin{abstract}
The age of digital transformation produced by industrial enterprises shifting to new forms of production and actively using versatile information and communications technologies has made issues with the management of digital potential especially vital. These trends have prompted the formation of integrated intellectual structures, called strategic innovatively active industrial clusters, whose primary unique feature is that they operate on a single digital platform. The purpose of this study is the construction of a structural-functional model for managing the digital potential of a strategic innovatively active industrial cluster to use for creating a methodology to assess this potential. The research methods include analysis and synthesis as well as graphic interpretation and content analysis. The main results of this study are as follows: a structural-functional model has been developed for use in managing the digital potential of a strategic innovatively active industrial cluster that harmoniously reflects the roles of all the subsystems forming the cluster, and a methodology has also been developed based on the created model to help measure the digital potential of a cluster, using one such cluster in the city of St. Petersburg, Russia as an example. The novelty of this study is in its development of a model that fully and comprehensively reflects the special features of managing the digital potential of newly integrated structures such as strategic innovatively active industrial clusters. In addition, the practical significance of the obtained results is that they can be used to calculate the real current values of the digital potential of these clusters and assist in the making of relevant management decisions for operational and strategic planning.
\end{abstract}

Keywords: Digital potential; Industrial cluster; Management model; Methodology to assess the digital potential; Single digital platform; Strategic innovatively active industrial cluster

\section{Introduction}

Active digitalization processes have prompted the formation and development of a new type integrated structure: the strategic innovatively active industrial cluster (SIAIC) (Tashenova and Babkin, 2017). The primary unique feature of this kind of cluster is that it operates on a single digital platform that has been actively introduced for the effective coordination of the activities of all participants in the cluster, including those of industrial, educational, financial, marketing and other enterprises. It should be noted that a

*Corresponding author's email: larisatash_88@mail.ru, Tel.: +7-701-5120348 
distinguishing feature of these clusters is that the participants do not need to be geographically coordinated as connectivity is ensured via the digital platform (Babkin et al., 2020). Separately studying the innovative activity of industrial clusters and the enterprises that form them is significant as understanding the levels of this activity and the degree to which the results of intellectual labor can be commercialized by industrial clusters (including by those of a new type) makes it possible to determine their evolution from a proto-cluster to an SIAIC (Afanasieva et al., 2018; Aleksandrova and Sokolitsyn, 2019; Babkin and Tashenova, 2019; Asaturova and Kochman, 2020).

Each year, the analytics company Clarivate publishes an analytical report called the Top 100 Global Innovators Report. This report contains the rankings of the leading innovative companies (including those in large industrial integrated structures, such as clusters, holdings, corporations and others.) based on the various innovative products that they have developed and introduced. In 2016, the following countries were the innovation leaders based on the number of innovative enterprises located within them: the United States (39\%), Japan (34\%) and France (10\%). The United States has a large share of innovators due to the concentration of large industrial enterprises and clusters in the country, such as California's life science clusters (Panetta, 2021). In 2021, the leader was again the United States (42\%) followed by Japan (29\%), while third place was shared by Taiwan (5\%) and South Korea (5\%) and the fourth place was taken by China (4\%). Switzerland, Germany and France were the followers, each having 3\% respectively. Many of the companies in Table 1 are big industrial consortiums. They are also members of regional and national innovatively active industrial clusters. It is important to note that in recent years, there have been a variety of works related and directly dedicated to the key development aspects of integrated industrial structures, namely clusters. It is common for the authors in this field to highlight the links between the level of a region's economic growth and the development of the industrial clusters and agglomerations within it (Chen et al., 2018) as well as those between the specifics of innovative development projects and the scale of the industrial production in clusters with a variety of levels of innovative activity (Delgado, 2020). Studies have also considered the links between the social status of a cluster and the establishment of new enterprises, the growth of mono-cities (Ivanova et al., 2018; Luo et al., 2020) and university and regional innovative development (Koroleva and Kuratova, 2020; Rodionov and Velichenkova, 2020). These researchers have also assessed the externalities and internalities that allow enterprises in clusters to create and use innovations (Martínez-Cháfer et al., 2021) and transfer technologies (Soares et al., 2020), and they have analyzed the degree to which clusters have affected the productivity levels of the enterprises that are their members (Stichhauerova et al., 2020).

Table 1 Five leading innovative companies worldwide

\begin{tabular}{cll}
\hline Company name & Country & \multicolumn{1}{c}{ Industrial sector } \\
\hline $3 \mathrm{M}$ & USA & Chemistry and materials \\
ABB & Switzerland & Industrial systems \\
Abbott & USA & Pharmaceuticals \\
AGC & Japan & Chemistry and materials \\
Aisin Seiki & Japan & Automotive \\
\hline
\end{tabular}

Note: compiled based on the report by the analytics company Clarivate, Top 100 Global Innovators 2021

A number of publications have sought to analyze the efficiency of cluster innovation policies (Fotso, 2021) and the formation and development of regional and national innovation systems and the methods for assessing them (Ksenofontova, 2015; Kulagina et al., 2019; Rudskaya et al., 2020; Gutiérrez et al., 2021). They have also studied the interplay 
between cluster structures and the service sector, including the matters related to meeting the needs of the sharing economy (Mamrayeva and Tashenova, 2017; Mamrayeva and Tashenova, 2020; Zhao et al., 2021).

Given the ever-growing role of information and communications technology and its specific use by SIAICs, new research areas have opened up and been explored in papers discussing the use of artificial intelligence, the industrial internet of things, big data and cyber-physical systems within smart manufacturing (Durana et al., 2021; Stornelli et al., 2021) as well as of the approaches to management that have resulted in new business models for the age of additive production (Bencsik, 2020; Patalas-Maliszewska and Topczak, 2021).

Some works have sought approaches for analyzing the level of economic security of a cluster (Polyanin et al., 2020), developing methods for assessing and monitoring cluster structures, including digital ones (Kudryavtseva et al., 2020; Lyukevich et al., 2020).

It is obvious that industrial clusters, including SIAICs, have been significantly affected by the COVID-19 pandemic, which has fundamentally changed the nature and quantity of the products being made and has altered the essence of production processes, logistics, investments and other cluster activities (Agus et al., 2021; Dai et al., 2021; Rodionov et al., 2021; Shevtsova et al., 2021), transferring them to the digital environment. Therefore, given the digital transformation of the economy that is currently taking place, the issues related to the management of the digital potential (DP) of industrial clusters, including of SIAICs, are relevant and important areas of study today. Accordingly, the purpose of this study is the creation of a structural-functional model built to help manage the DP of an SIAIC. Furthermore, the objectives of study are to identify the subsystems and ecosystems of the constructed model, determine the position of the organizational economic management mechanism and use the model to elucidate the DP in a case study of the following cluster: Developing Information Technology, Radio Electronics, Tool Engineering, Communications Means and Infotelecommunications of St. Petersburg.

For the most part, the analysis shows that we still currently face an acute problem related to the management of the DP of a new type of industrial enterprise, namely the SIAIC, thus confirming the significance and relevance of the research presented in this paper. Thus, the authors consider an innovatively active industrial cluster as the object of this study, while the purpose of this study is the development a structural-functional model for managing the DP of an SIAIC to help devise a methodology for assessing the DP of the cluster.

\section{Methods}

In This study adopts general scientific methods, including analysis, which is used for evaluating the most innovatively active industrial enterprises worldwide broken down by sector and highlighting the key components of the structural-functional DP management model for SIAICs, and synthesis, which is applied for systematizing the subsystems of the model and presenting them as a whole of interconnected components. This paper also employs content analysis, which is used to study the existing academic publications dedicated to the analyzed problems and found via scientometric databases, and graphic interpretation, which allows the authors to illustrate their developed structural-functional management model.

It should be noted that the content analysis was performed based on a study of the results of a search on the Clarivate Analytics database. Based on the query "digital potential + industrial cluster", 135 results were analyzed that were directly or indirectly related to the topic of the query, including scientific articles presented in such journals as Advanced 
Engineering Informatics (2020), Technology Innovation Management Review (2019), Computers and Industrial Engineering (2020), Journal of Modeling in Management (2021; early access), Journal of Digital Imaging (2018), Journal of Industrial Information Integration (2021; early access), Multimodal Technologies and Interaction (2021) and others. Further limiting the search by choosing the years 2019-2021 and also leaving only the heading "Review Articles", a general analysis was made of 64 issues from such subject classifications as business, management, computer science interdisciplinary applications, computer science information systems, engineering manufacturing, engineering multidisciplinary and many others. Finally, a pool of articles directly related to the research problem being considered was selected.

Economic and statistical methods as represented by correlation-regression analysis were adopted for the validation of the selection of the indicators for use in assessing the DP of the SIAIC. The following can be highlighted as the main stages of this study: the formulation of its purpose and objectives, development of the model and characterization of its components, creation of the methodology to assess the DP of the SIAIC based on the model and test of the model.

\section{Results and Discussion}

The relevant aspects of an integrated structure such as an SIAIC, its operations in the current market and its technological transformation are important concerns in the specifics of DP management (Mizanbekova et al., 2020; Nadkarni and Prügl, 2021; Verhoef et al., 2021). We believe that the structural-functional DP management model of the SIAIC should be understood as a system of interrelated components represented by externalities (factors of the macro-environment) and internalities (factors of the micro-environment), the subjects and objects of management, the key components of the organizational-economic management mechanism and the interactions that take place on the single digital platform to ensure the connectivity of the production and business operations of all the participants in the SIAIC (Babkin et al., 2019; Tashenova et al., 2020). Figure 1 presents the components of the model.

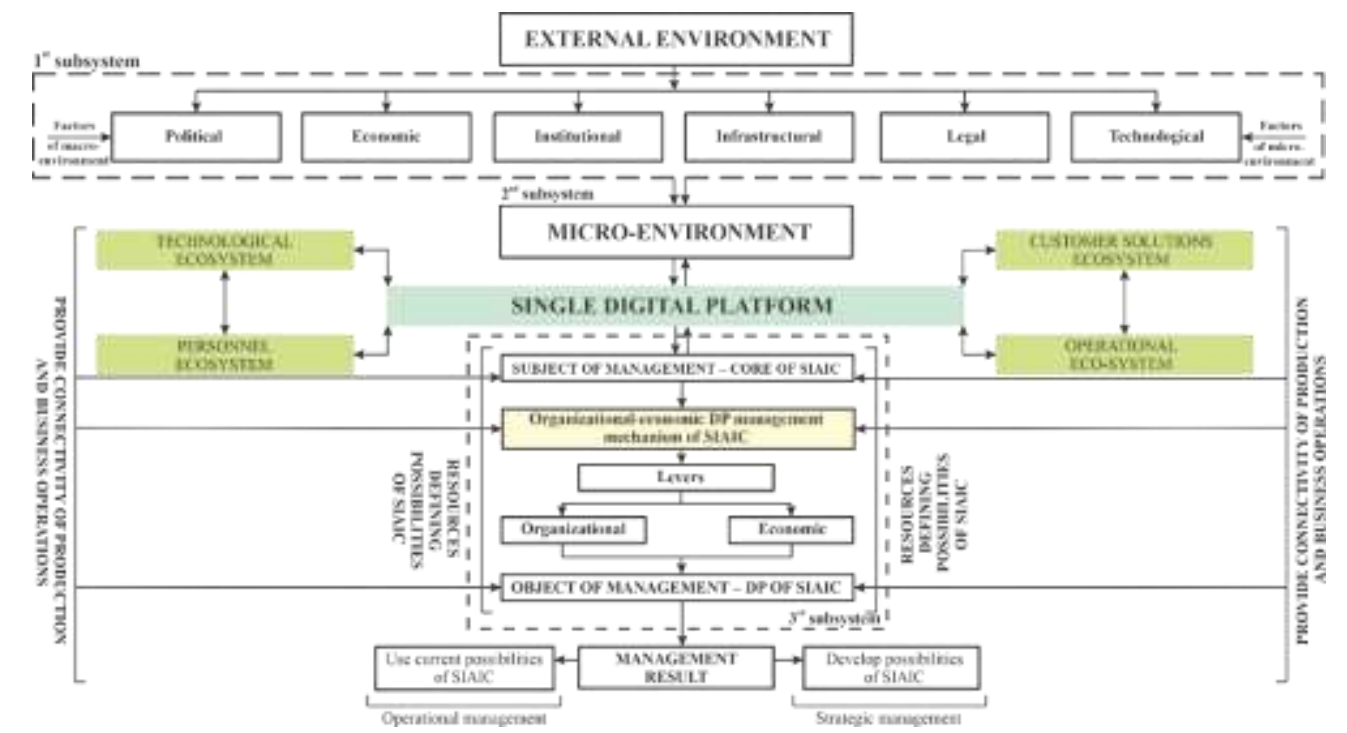

Figure 1 Structural-functional digital potential management model of a strategic innovatively active industrial cluster

Thus, the structural-functional DP management model for an SIAIC includes three key subsystems: the first is comprised of a set of factors representing the macro-environment, 
including political, economic, institutional, infrastructural, legal and technological factors; the second reflects the micro-environment of the cluster, including the core of the SIAIC, supporting enterprises, industrial companies, target audiences, competitors and others; and the third includes the main components of the management system, such as the subject (company-core of the SIAIC) and object of management (DP of the cluster), levers (organizational and economic ones) and the organizational-economic DP management mechanism of the SIAIC. The consistency of the subsystems in the presented model is ensured via a single digital platform, whose ecosystems are specified in Figure 2.

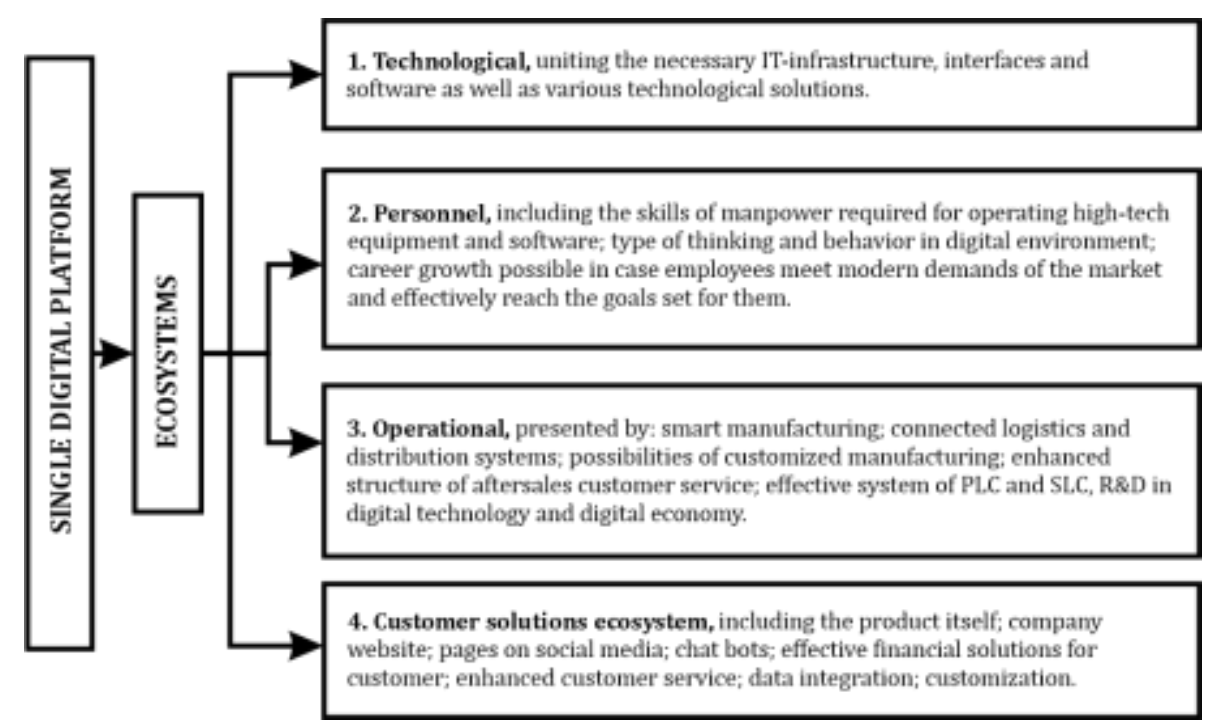

Figure 2 Ecosystems of the single digital platform of a strategic innovatively active industrial cluster

Thus, according to Figure 2, we can highlight four key ecosystems in the platform structure: technological, responsible for all the technical decisions necessary for providing the production, operational and management processes implemented using a variety of information tools and software; personnel, providing the cluster with the required human resources with the relevant cutting edge and digital skills for working with technologies such as robotized equipment, digital factories, high-precision equipment and others; operational, including direct smart manufacturing, logistic processes, customized productmaking, after-sales customer service and more; customer-adapted/customer solutions, including aspects of product and service making and promotion, software solutions created to minimize time and improve communication with customers, the company/cluster official website, pages on social media (including professional ones), chat bots, telegram bots and a range of means and possibilities for the online payment for goods, work and services provided.

The model is the basis for developing the methodology to assess the DP of an SIAIC (Tashenova et al., 2020) as presented on Figure 3.

The term "strategic innovatively active industrial cluster" was introduced into scientific circulation by the authors of this article and is thus a new term; therefore, other studies aimed at the assessment and management of the DP of such complex integrated structures, based on the studies carried out by the authors, were not found. However, it is important to note that there have been a number of studies that have proposed to evaluate the DP of an enterprise as a type of integral assessment, including of indicators of the external and internal environment (Kozlov and Teslya, 2019). Others studies have sought to assess DP by taking into account the indicators based on the provision of organizations with advanced hardware and software systems, level of automation of certain business 
processes of enterprises and volume of costs for the development of the IT sphere (Gorodnova and Peshkova, 2018). Still others have assessed DP within the context of two groups of parameters: indicators of the development of the digital infrastructure of the region and indicators of general structural trends of the region (Kovalchuk and Alekseev, 2017).

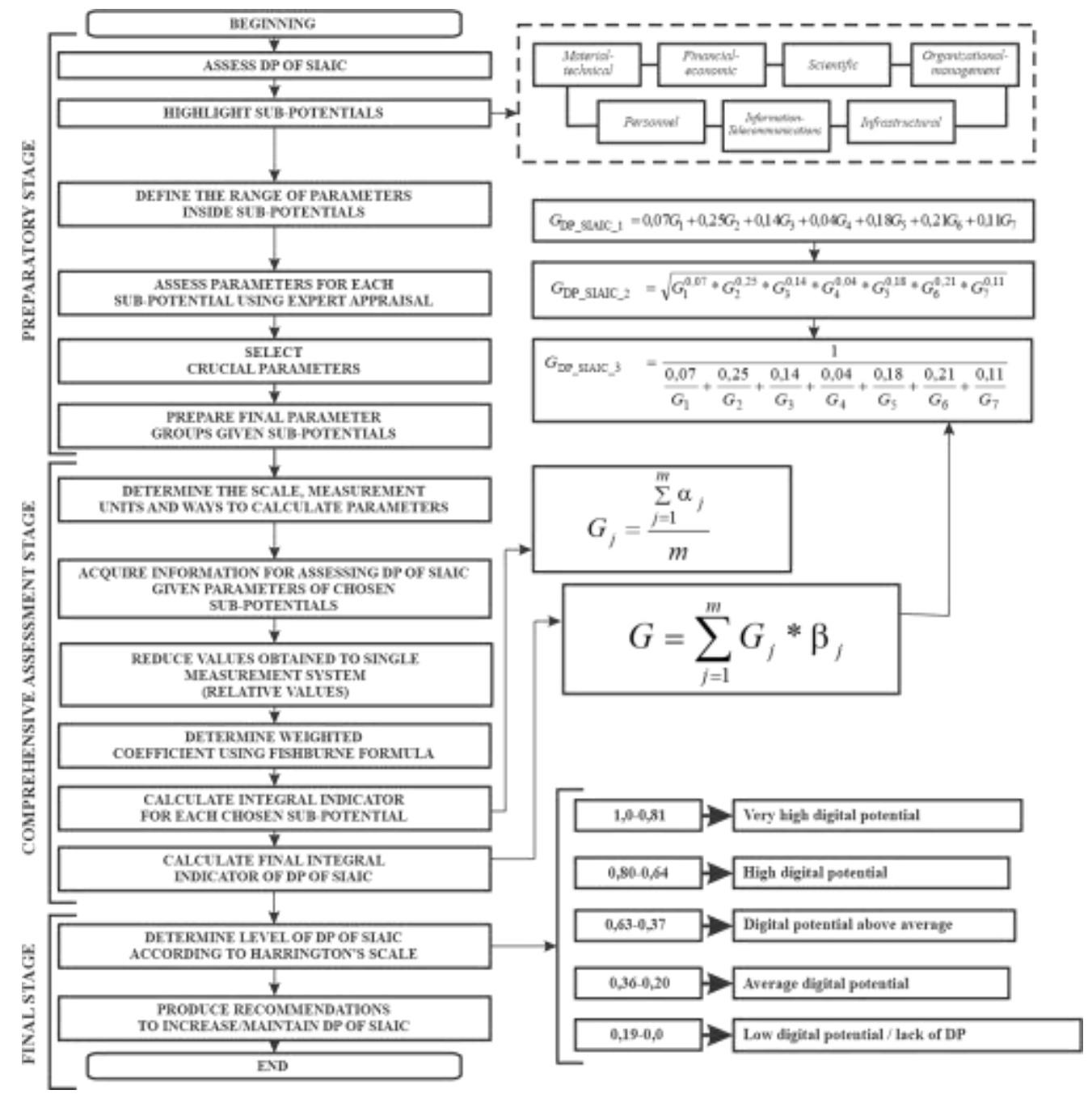

Figure 3 Methodology for assessing the digital potential of strategic innovatively active industrial clusters

The authors' methodology validates seven sub-potentials and the 32 parameters that form them. Then they were used for measuring the level of the DP of the studied cluster, namely Developing Information Technology, Radio Electronics, Tool Engineering, Communications Means and Infotelecommunications of St. Petersburg, which has the following core activities: radioelectronics and information technology.

Today, 295 enterprises are members of the analyzed cluster. They vary in size and include, among others, the Russian Association of Developers, JSC All-Russian Research Institute of Radio Equipment, the Council of Rectors of St. Petersburg, JSC Avangard, JSC Svetlana, the JSC Kozitsky Plant and the JSC Russian Institute of Radio Navigation and Time.

Using the methodology presented above and developed on the basis of the structuralfunctional management model, let us calculate the size of the DP of the cluster: based on the weighted arithmetic mean, it is 0.65 (high DP); based on the weighted geometric mean, it is 0.77 (high DP), and based on the weighted harmonic mean, it is 0.53 (high DP). 
The results obtained on the basis of the structural-functional DP management model of the SIAIC and the authors' assessment methodology can be used by the cluster's management to make further operational and strategic decisions concerning current DP management in two key directions: (1) when the DP is rational (it is approved by the cluster management and DP corresponds to the key production and business processes of the cluster); or (2) when it requires revision.

In the first case, the DP management process is correct, all "levers" work set in "regular mode" and allow the SIAIC to achieve its set goals and objectives. If the result obtained requires clarification, for example, if it is not accurate enough or the management of the company decides to change the main components of the DP, then we should return to the initial data and consider the possibility of activating the work of all cluster members on the implementation and widespread use of existing digital information and communication technologies.

In general, this study has a pronounced relevance and scientific novelty as no prior publications on the assessment and management of the DP of SIAICs has been found, and thus, this study can help fill the niche of scientific research related to this issue.

\section{Conclusions}

The structural-functional DP management model of an SIAIC developed in this article is presented as the set of interrelated components that comprise it, indicating its scientific novelty. Most important is the digital platform that can be used to coordinate all activities among participants as well as provide an organizational economic mechanism for managing DP.

The model that was built was used to form the methodology for assessing the DP of the studied SIAIC, thus calculating the actual DP values of a genuine operational industrial cluster. This proves that the model and methodology are appropriate and applicable for the performance of practical calculations.

In their further research, the authors plan to study the special features of toolformation and the scientific-methodological provision of DP management of SIAICs for the period of digital transformation of enterprises and clusters based on the concept of Industry 5.0 as a new trend for social and economic reforms.

The limitations of future research will be related to the study of the possibilities for replacing the sets of quantitative and qualitative data that can be included, taking into consideration of the changes caused by Industry 5.0, in the integrated assessment of DP in the context of the subpotentials identified in the present study and reflected in the created methodology.

\section{Acknowledgements}

This research is partially funded by the Ministry of Science and Higher Education of the Russian Federation under the strategic academic leadership program Priority 2030 (Agreement 075-15-2021-1333, dated 30.09.2021).

\section{References}

Afanasieva, N.V., Rodionov, D.G., Vasilev, Y.N., 2018. System of Indicators of Coal Enterprise Competitiveness Assessment. Espacios, Volume 39(36), pp. 1-10

Agus, A.A., Yudoko, G., Mulyono, N., Imaniya, T., 2021. E-Commerce Performance, Digital Marketing Capability and Supply Chain Capability within E-Commerce Platform: Longitudinal Study Before and After COVID-19. International Journal of Technology, 
Volume 12(2), pp. 360-370

Aleksandrova, A.I., Sokolitsyn, A.S., 2019. Optimization of the Distribution of State Support

Funds across National Innovation Clusters. In: 33 ${ }^{\text {rd }}$ IBIMA Conference: April 10-11, 2019, Granada, Spain, pp. 1644-1651

Asaturova, Y., Kochman A., 2020. Innovative Activity as a Key Factor in the Formation of Innovative Potential of Enterprise. In: European Conference on Innovation and Entrepreneurship, September 17-18, 2020, Rome, Italy, pp. 84-93

Babkin, A., Tashenova, L., Mamrayeva, D., Azimov, P., 2019. Development of Algorithm to Assess Digital Potential of High-Tech Industrial Cluster. In: ACM International Conference Proceeding Series, October 24-25, 2019, St. Petersburg, Russia, pp. 1-7

Babkin, A.V., Tashenova, L.V., 2019. Backbone Innovative-Active Industrial Cluster: Genesis Development. In: Digital Transformation of Economy and Industry (DTEI) 2019, June 20-22, 2019, St. Petersburg, Russia, pp. 180-191

Babkin, A.V., Tashenova, L.V., Mamrayeva, D., Makmudova, G., 2020. Digital Platforms for Industrial Clusters and Enterprises: Essence and Structure. In: ACM International Conference Proceeding Series, October 22-23, 2020, St. Petersburg, Russia, pp. 1-7

Bencsik, A., 2020. Challenges of Management in the Digital Economy. International Journal of Technology, Volume 11(6), pp. 1275-1285

Chen, Y., Xi, M., Liao, K., Wang, F., 2018. The Relationship between Economic Growth and the Development of Industrial Cluster and City Group. International Journal of Technology, Policy and Management, Volume 18(2), pp. 155-163

Dai, R., Mookherjee, D., Quan, Y., Zhang, X., 2021. Industrial Clusters, Networks and Resilience to the Covid-19 Shock in China. Journal of Economic Behavior and Organization, Volume 183, pp. 433-455

Delgado, M., 2020. The Co-Location of Innovation and Production in Clusters. Industry and Innovation, Volume 27(8), pp. 842-870

Durana, P., Perkins, N., Valaskova, K., 2021. Artificial Intelligence Data-Driven Internet of Things Systems, Real-Time Advanced Analytics, and Cyber-Physical Production Networks in Sustainable Smart Manufacturing. Economics, Management, and Financial Markets, Volume 16(1), pp. 20-30

Fotso, R., 2021. Evaluating the Indirect Effects of Cluster-Based Innovation Policies: The Case of the Technological Research Institutes in France. The Journal of Technology Transfer, Volume 2021, https://doi.org/10.1007/s10961-021-09865-2

Gorodnova, N.V., Peshkova, A.A., 2018. Theoretical Basics Development of Industrial Enterprises Digital Potential Assessment. Diskussiya [Discussion], Volume 5(90), pp. 74-84

Gutiérrez, C., Verónica R.P., Smith, J., 2021. The Chilean Sectoral Innovation Systems: An Approach from the National Innovation Survey. Journal of Technology Management and Innovation, Volume 16(1), pp. 3-13

Ivanova, O.P., Trifonov, V.A., Nesteruk, D.N., 2018. Crucial Factors Providing Sustainable Development of Industrial Clusters in a Priority Social and Economic Development Area of Single-Industry Towns. Espacios, Volume 39(26), pp. 1-26

Koroleva, E., Kuratova, A., 2020. Higher Education and Digitalization of the Economy: The Case of Russian Regions. International Journal of Technology, Volume 11(6), pp. 11811190

Kovalchuk, Yu.A., Alekseev, I.V., 2017. The Digital Potential of Regional Markets as a New Strategic Factor in the Development of Franchise Businesses. Bulletin of the South Ural State University Series Economics and Management, Volume 11(2), pp. 149-158

Kozlov, A., Teslya, A., 2019. Digital Potential of Industrial Enterprises: Essence, 
Determination and Calculation Methods. Transbaikal State University Journal, Volume 25(6), pp. 101-110

Ksenofontova, O.L., 2015. The Foreign Countries Experience in Cluster Establishing and Functioning: A Model-Based Approach. Modern High Technologies. Regional Application, Volume 2(42), pp. 36-42

Kudryavtseva, T., Kulagina, N., Lysenko, A., Berawi, M.A., Skhvediani, A., 2020. Developing Methods to Assess and Monitor Cluster Structures: The Case of Digital Clusters. International Journal of Technology, Volume 11(4), pp. 667-676

Kulagina, N.A., Mikheenko, O.V., Rodionov, D.G., 2019. Technologies for the Development of Methods for Evaluating an Innovative System. International Journal of Recent Technology and Engineering (IJRTE), Volume 8(3), pp. 5083-5091

Luo, L., Ma, X., Makino, S., Shinkle, G.A., 2020. Cluster Status and New Venture Creation. Journal of Business Venturing, Volume 35(5), https://doi.org/10.1016/j.jbusvent.2019.105985

Lyukevich, I., Agranov, A., Lvova, N., Guzikova, L., 2020. Digital Experience: How to Find a Tool for Evaluating Business Economic Risk. International Journal of Technology, Volume 11(6), pp. 1244-1254

Mamrayeva, D., Tashenova, L., 2017. Prospects of Bicycle-Sharing in Urban Tourism in the Republic of Kazakhstan: Myth or Reality? Transport Problems, Volume 12(2), pp. 65-76

Mamrayeva, D., Tashenova, L., 2020. Methodological Tools for Assessing the Region's Tourist and Recreation Potential. Economy of Region, Volume 16(1), pp. 127-140

Martínez-Cháfer, L., Molina-Morales, F.X., Roig-Tierno, N., 2021. Explaining Technological Innovation of the Clustered Firms: Internal and Relational Factors. Journal of Small Business Management, pp. 1-32, https://doi.org/10.1080/00472778.2021.1883035

Mizanbekova, S., Bogomolova, I., Shatohina, N., 2020. Prospects for Digital and Innovative Technologies in Management Competitiveness of Enterprises. Food Processing: Techniques and Technology, Volume 50(2), pp. 372-383

Nadkarni, S., Prügl, R., 2021. Digital Transformation: A Review, Synthesis and Opportunities for Future Research. Management Review Quarterly, Volume 71(2), pp. 233-241

Panetta, J., 2021. A Tale in Three Parts: The Success of California's Life Science Clusters. Journal of Commercial Biotechnology, Volume 26(1), pp. 40-42

Patalas-Maliszewska, J., Topczak, M., 2021. A New Management Approach based on Additive Manufacturing Technologies and Industry 4.0 Requirements. Advances in Production Engineering and Management, Volume 16(1), pp. 125-135

Polyanin, A., Pronyaeva, L., Pavlova, A., Fedotenkova, O., Rodionov, D., 2020. Integrated Approach for Assessing the Economic Security of a Cluster. International Journal of Technology, Volume 11(6), pp. 1148-1160

Rodionov, D., Velichenkova, D., 2020. Relation between Russian Universities and Regional Innovation Development. Journal of Open Innovation: Technology, Market, and Complexity, Volume 6(4), pp. 1-26

Rodionov, D.G., Konnikov, E.A., Nasrutdinov, M.N., 2021. A Transformation of the Approach to Evaluating a Region's Investment Attractiveness as a Consequence of the COVID-19 Pandemic. Economies, Volume 9(2), pp. 1-20

Rudskaya, I., Ozhgikhin, I., Kryzhko, D., 2020. Developing and Testing an Algorithm to Identify Future Innovative Research Areas in Digitalization Conditions (Using a Medical-Sector Example). International Journal of Technology, Volume 11(6), pp. 12131222

Shevtsova, S., Janovska, K., Strapolova, D., Kuzin, I., Kutac, J., Kutac, T., 2021. Modelling Innovative Logistic Clusters for Reinforcing International Economic Integration using 
an Example of a Metallurgical Complex. Acta Logistica, Volume 8(1), pp. 83-93

Soares, J., Romero, F., Lopes Nunes, M., 2020. Innovation and Technology Transfer: A

Framework for Clustering Intermediation Roles. In: 2020 IEEE International Conference on Technology Management, Operations and Decisions, ICTMOD, November 24-27, 2020, Marrakech, Morocco, pp. 1-6

Stichhauerova, E., Zizka, M., Pelloneova, N., 2020. Comparison of the Significance of Clusters for Increasing Business Performance. Journal of Competitiveness, Volume 12(3), pp. 172-189

Stornelli, A., Ozcan, S., Simms, C., 2021. Advanced Manufacturing Technology Adoption and Innovation: A Systematic Literature Review on Barriers, Enablers, and Innovation Types. Research Policy, Volume 50(6), pp. 1-18

Tashenova, L., Babkin, A., Mamrayeva, D., Babkin, I., 2020. Method for Evaluating the Digital Potential of a Backbone Innovative Active Industrial Cluster. International Journal of Technology, Volume 11(8), pp. 1499-1508

Tashenova, L.V., Babkin, A.V., 2017. Backbone Innovation-Active Industrial Cluster in the Conditions of Digital Transformation: Concept, Essence, Features. In: Proceedings of the Scientific and Practical Conference with International Participation: "Economic and Management in the Context of Digitalization: State, Problems, Foresight", December 25, 2019, St. Petersburg, Russia, pp. 301-313

Verhoef, Peter C., Broekhuizen, T., Bart, Y., Bhattacharya, A., Qi Dong, J., Fabian, N., Haenlein, M., 2021. Digital Transformation: A Multidisciplinary Reflection and Research Agenda. Journal of Business Research, Volume 122, pp. 889-901

Zhao, L., Ruan, J., Shi, X., 2021. Local Industrial Policies and Development of Agricultural Clusters: A Case Study based on a Tea Cluster in China. International Food and Agribusiness Management Review, Volume 24(2), pp. 267-288 